\title{
Applicability and Efficiency of Socio-Cultural Inspired Algorithms in Optimizing Mechanical Systems - A Critical Review
}

\author{
Sanket Patel, Ganesh M. Kakandikar*, Omkar Kulkarni \\ School of Mechanical Engineering, M.I.T. World Peace University, Pune 411038, Maharashtra, India
}

Corresponding Author Email: kakandikar@gmail.com

https://doi.org/10.18280/rces.070203

Received: 15 February 2020

Accepted: 10 May 2020

\section{Keywords:}

social, cultural, optimization, algorithm, mechanical applications

\begin{abstract}
In the recent years' optimization algorithms are used in many real-life applications to get the best out of everything. There are many types of optimization algorithm such as Nature inspired algorithm, Bio-Inspired algorithm which also have their applications. This paper aims to presents different category of algorithms and their applications, which are inspired by the social behavior of humans in groups termed as family. These algorithms are widely appreciated by researchers from various domains for optimization. The performance of social algorithm (SA) to discover the global optimum solution for the constrained, unconstrained and multi-objective optimization problems is sound. This paper extensively reviews and presents the applicability and also efficiency of the socio-inspired algorithm in solving real life problems in the field of mechanical engineering mechanical engineering problems.
\end{abstract}

\section{INTRODUCTION}

Over the recent few decades, a number of algorithms are introduced in the optimization field. The literature indicates that these algorithms played an active role in solving constrained, unconstrained and multi-objective engineering problems. Socio inspired algorithms are a subset of nature inspired/bio inspired algorithms. In the initial phase of development, researchers were more fascinated with evolution strategies as Evolutionary Algorithms (EA) [1]. Swarm Intelligence (SI) offers more advantages as multiple solutions in each iteration as well as cooperation between solutions to locate global optimum [2]. This includes Particle Swarm Optimization (PSO) [3, 4], Cuckoo Search Algorithm (CS) [5, 6], Grey Wolf Optimizer (GWO) [7, 8], Artificial Bee Colony Algorithm (ABC) [9], Firefly Algorithm (FA) [10], Ant Colony Optimizer (ACO) [11], Cat Swarm Optimizer (CSO) [12], Bat Algorithm (BA) [13], Simulated Annealing [14], Artificial Immune Systems (AIS) [15], Tabu Search (TS) [16], Harmony Search (HS) [17], Artificial Fish School Algorithm (AFS) [18], Social Cognitive Optimization (SCO) [19], Honey-Bees Mating Optimization (HBMO) Algorithm [20], Gravitation Search Algorithm (GSA) [21], Bat Search (DS) Algorithm [22], Flower Pollination Algorithm (FPA) [23], Social Spider Optimization (SSO) [24], Chemical Reaction (CR) Algorithm [25], Bull Optimization Algorithm [26], Elephant Herding Optimization (EHO) [27], Whale Optimization (WO) Algorithm [28], The Ant Lion Optimizer [29], Moth-Flame Optimization Algorithm [30], Sine-Cosine Algorithm [31], Dragonfly Algorithm [32], Salp Swarm Algorithm [33, 34], Grasshopper Optimization (GO) Algorithm [35, 36], etc. The evolutionary algorithm includes Genetic Algorithm (GA) [37, 38], Genetic programming and Differential Evolution (DE) [38], etc.
Last few years, researches have been attracted to human behavior in groups, social interaction and influence, which resulted in many algorithms termed as Socio Cultural algorithms. Figure 1 shows the comprehensive classification of Social/Cultural-Algorithms (SA) [39]. The different types of Socio-Inspired algorithms are solicited in Table 1. Due to their simple and easy fundamentals for determining optimal solutions to the intricate and real-world computational problem, all these techniques had achieved proper attention [40].

Table 1. A list of socio-inspired algorithms [40]

\begin{tabular}{ccc}
\hline Algorithm & Author & Year \\
\hline Social-Emotional Optimization & Xu et al. & 2010 \\
Algorithm & Wenge Lv et & \\
Election Campaign Optimization & al. & 2010 \\
Algorithm & Atashpaz et al. & 2007 \\
Imperialist Competitive Algorithm & Ahmadi & 2011 \\
Anarchic Society Optimization & Kashan & 2009 \\
League Championship Algorithm & Kulkarni et al. & 2013 \\
Cohort Intelligence & Moosavian et & 2014 \\
Soccer League Competition Algorithm & al. & Year \\
Algorithm & Author & \\
Society and Civilization Optimization & Ray et al. & 2003 \\
Algorithm & Emami et al. & 2015 \\
Election Algorithm & Rao et al. & 2011 \\
Teaching Learning Based & Satapathy et & 2016 \\
Optimization & al. & 2016 \\
Socio Group Optimization & Liu et al. & 2016 \\
Social Learning Optimization & Huan et al. & 2016 \\
Ideology Algorithm & Kuo et al. & 2013 \\
\hline Cultural Evolution Algorithm & &
\end{tabular}




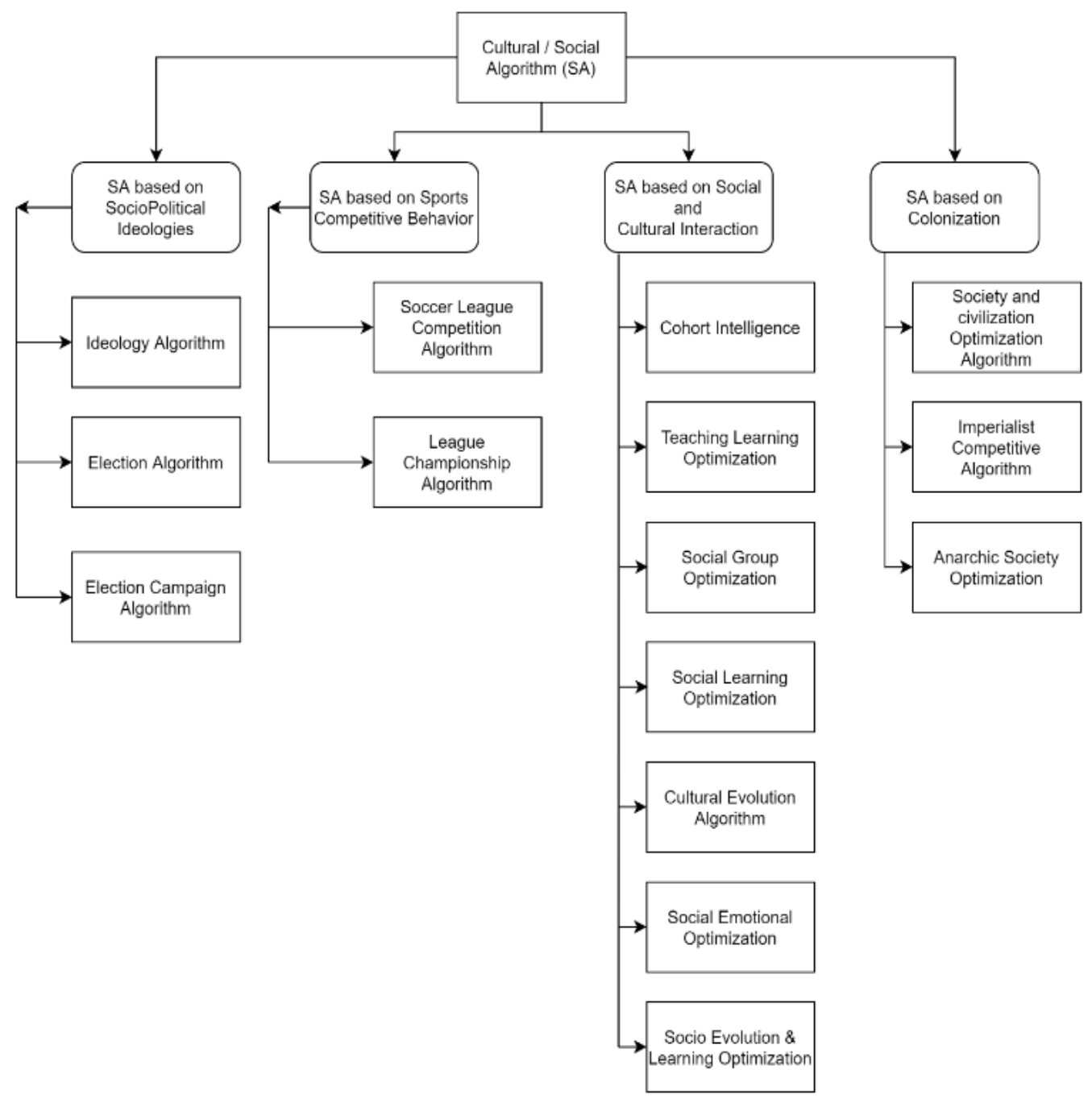

Figure 1. Classification of socio-inspired algorithms [41]

The preceding section has discussed ideologies and developments in Social Inspired algorithms in detail. It is observed that many researchers have contributed to this domain with wide variety of social phenomenon. Mechanical Engineering is major branch of engineering designing and manufacturing complicated mechanical systems. Manufacturing involved is core of mechanical engineering. Philosophies implemented for enhancement of production quality and efficiency has many real worlds complicated multi objective and multi constrained problems with numerous variables. The paper presents applicability of family of these algorithms and their efficiency in finding global solutions to mechanical engineering.

\section{SOCIO-INSPIRED ALGORITHMS}

\subsection{Society and civilization optimization algorithm}

Ray et al. [42] proposed the Society and Civilization Optimization (SCO) algorithm. The essential theory behind social behavior (e.g., human society, insect society, etc.) is a mutual interaction between humans which is predominant. This is the powerful perception behind the optimization algorithm. The proposed SCO algorithm is extremely helpful for solving the single objective constrained optimization problem. Each society is a set of points which resembles each solution and such clusters of points form civilization. Every individual in society form the position and interact with each other to form set of another society and civilization. Over iterations, civilization evolves and advances and reaches the optimum point.

Ray et al. [42] applied Society and Civilization Optimization (SCO) algorithm to four engineering structure issues; welded beam configuration, spring design, speed reducer design and fourth is three-bar truss design. All four problems are well defined single-objective engineering design issues. The results obtained are encouraging and proves that algorithm can efficiently arrive at optimum solutions as compared to existing solutions. Furthermore, the algorithm employs a novel non-dominance scheme to handle constraints that eliminates the problem of scaling and aggregation that is common among penalty-function-based methods.

\subsection{Imperialist competitive algorithm}

Imperialist Competitive algorithm (ICA) was originally proposed by Lucas [43]. It is population - based metaheuristic algorithm. Imperialism was suffering from the theory referred to as mercantilism. Initially random points are generated called as initial countries and imperialists [44]. At the initial stage of the ICA, each population is characterized as a rustic and best country (best solution) which is selected as imperialist and essentially separated into two groups supporting their 
supremacy, i.e. colonies and imperialist which form empire. Over the time evolution the weak empire falls and new empire is formed. Finally, only one empire and its colonies remain over a stipulated time which are known as final solution and position. In several engineering applications like control [45], data clustering [46], industrial management [47] the proposed algorithm has been effectively operated.

Parallel machine scheduling problem [PMSP] is major concern when distributing production facilities. Recent developments made it imperative to think on low carbon emissions and energy consumption. The objectives involve optimum cutting speeds, low energy consumption, low delay times etc. Pan et al. [48] studied PMSP with total tardiness (key objective) and total energy consumption with novel Imperialist Competitive Algorithm [ICA]. After extensive experimentation they concluded that ICA has advantages on others such as Ant Colony optimization for low carbon PMSP.

Japanese management philosophies such as Just in Time drastically changed the design of shop floor production flow. U-type production flow is preferred over line and L-type. Nourmohammadi et al. [49] presented multi-objective U-type assembly line balancing problem. The main objectives are enhancement in line efficiency and minimizing variation of work load. They applied an Imperialist Competitive Algorithm to solve this problem. The results achieved were compared with that of Genetic Algorithm [GA] and it is observed that it outperforms GA.

Energy independence is most influencing parameter these days indicating development of any country. Everyone in the world is working on saving energy. Natural gas is one of the important energy sources used as a fuel in different plants. Gas turbines performance to exhibit maximum efficiency are based on standard air temperature, pressure and relative humidity. Optimum combination of these environmental and operational conditions leads to maximum efficiency. An exergy analysis is needed to locate the source and the magnitude of thermodynamic inefficiencies in a thermal system. This provides useful information for improving the overall efficiency and cost effectiveness of a system and comparing the performance. Morteza Bayareh employed Imperialist Competitive Algorithm [50] to enhance the efficiency of thermal system in turbine. Single-objective and multiobjective optimization problem was solved using sociopolitical relationship of countries as per philosophy of algorithm. Exergy destruction, exergy efficiency and specific fuel consumption of several actual conditions were defined for all the compressor station components by exergy analysis equations. The mathematical models were employed to predict some of the operational parameters by operational and environmental variables. Results of this optimization revealed that application of this novel algorithm, can lead to a significant decrease in the computational time.

Heat exchangers are devices used to transfer heat between two or more fluids that are at different temperatures and which in most of the cases they are separated by a solid wall. Hadidi et al. [51] shows another design approach for shell-and-tube heat exchangers utilizing the Imperialist Competitive Algorithm (ICA) from a financial perspective. The fundamental goal of this paper was cost minimization of shelland-tube heat exchangers (STHE). The design variables studied were tube length, tube external width, pitch size and baffle spacing [52]. The design of STHEs involves a large number of geometric and operating variables as a part of the search for an exchanger geometry that meets the heat duty requirement and a given set of design constrains [53]. In present study, ICA technique has been applied to minimize the total cost of the equipment including capital investment and the sum of discounted annual energy expenditures. Referring to the literature test cases, reduction of capital investment up to $6.1 \%$ and savings in operating costs up to $94 \%$ were obtained, with an overall decrease of total cost up to $53 \%$, showing the improvement potential of the proposed method.

Heat transfer rate of heat exchangers especially for singlephase flows can be improved through many enhancement techniques. Karami et al. [54] used the Imperialist Competitive Algorithm [ICA] to optimize of the heat transfer in an aircooled heat exchanger equipped with the classic twisted tape inserts. They conducted experiments with twist ratio range from 1.76 to 3.53 with varied, Reynolds number from 4021 to 16,118. Regression equation of average Nusselt number was obtained as a function of Reynolds number and the twist ratio from data. Then the cost function was optimized by the use of ICA. Simplicity, accuracy, and time saving are some of advantages of the ICA algorithm.

High transfer efficiency makes compact heat exchangers (CHEs) widely used in industrial applications that help saving material and space for a specified heat duty. Heat exchangers are designed for geometrical and operational parameters for specific working requirements. Plate fin heat exchangers are more popular in automobile, chemical and petrochemical industry. Yousefi et al. [55] utilized an Imperialist Competitive Algorithm (ICA) to design cross stream plate-fin heat exchanger. Minimizing total weight and annual cost were objective functions. Seven design parameters, namely, fin height, fin-strip length, heat exchanger length at hot and cold sides, fin frequency, fin thickness, and number of hot side layers are selected as optimization variables. The numerical results reveal that ICA can find optimum configuration with higher accuracy in less computational time when compared to conventional genetic algorithm.

\subsection{League championship algorithm}

The League Championship algorithm (LCA) is first proposed by Rezaei et al. [56]. It is based on the evolutionary population-based algorithm (EA) for locating global optimum during a continuous search space. The LCA plans to move a population of probable solutions to a promising area of the search space while finding the optimum. This algorithm actually runs a virtual competition of sports leagues over weeks [57]. In LCA, week states iteration and league ask population; construction of team stands for the solution. Initially, teams are introduced, which then play with each other to try to win, which resembles the finding of the optimum solution. For the team's objectives, alteration a fitness value was calculated for every team then after new solutions are generated for next week by applying operators to every team, which supports the results of match analysis ultimately to improve the previous solution.

Kashan [58] worked on five mechanical domain problems. Optimization of weight of the tension/compression spring with constraints as minimum deflection, shear stress, surge frequency and limits on outside diameter. Second one is minimizing the cost of a welded beam subject to constraints on shear stress, bending stress in the beam, buckling load on the bar and end deflection of the beam. The design variables are the thickness of the weld, length of the weld, width of the beam, and the beam thickness. Third problem is about the 
weight of a speed reducer to be minimized subject to constraints on bending stress of the gear teeth, surface stress, transverse defections of the shafts and stresses in the shaft. Forth problem is of design of pressure vessel with the objective of minimizing the total cost, including the cost of the materials, forming and welding. There are four design variables: Thickness of the shell, thickness of the head, the inner radius, and the length of the cylindrical section of the vessel. Last problem is design of a three-bar truss structure in which the volume should be minimized subject to stress constraints. The problem has two decision variable and three nonlinear constraints. Unlike other engineering design problems. All these problems were optimized using League championship algorithm (LCA). Computational results signify that with a smaller number of evaluations, LCA ensures finding the true optimum of these problems.

Metal Matrix Composites (MMC) are mostly used in the industries for the purpose of enhancing strength and other mechanical properties. Kumar et al. [59] in their research work on metal matrix composition (MMC) selected optimum manufacturing parameters utilizing League Championship Optimization (LCA) algorithm. They were designing MMC utilizing magnesium alloy and tungsten carbide. These two materials have been selected for making lightweight and highquality MMC for aeronautical and vehicle parts manufacturing. The overall performance analysis proves the effectiveness of the optimization technique.

\subsection{Social-emotional optimization algorithm}

A Social-Emotional Optimization Algorithm (SEOA) is an innovative collection brain optimization algorithm, this has been encouraged by choice behavior in human culture. In this algorithm the simulated world is defined and humans referring to solutions are defined. In human society, people do work very hard to extend their social status. To get a better reward from society, people will try their best to seek out the trail. Humans by interacting and cooperating with each other try to attain higher social status. This resembles the obtaining of optimum solution. Encouraged by this wonder, Xu et al. [60] introduced a new technique, social-emotional optimization algorithm (SEOA) during which the most individuals aim to extend the societal status.

\subsection{Election campaign algorithm}

In human society, the foremost important political activity is election. Within the election, a campaign is a crucial behavior. In election candidates attempt to find supreme votes from voters by a series of campaigns. This algorithm is known as Election Campaign Algorithm (ECO) which is proposed by Lv et al. [61] and it is a replacement heuristic algorithm. In ECO, voters are imagined as solution space and candidates are imagined as a current solution. The function value of the feasible solution is named as the prestige of a voter and performance value of a current solution is named as the prestige of a candidate. Many citizens are affected by a candidate, and his effect from candidates to voters will decrease progressively with the rise of the distance between the candidates and voters. Repeat the method circularly until the position of solution is found, which is the optimal solution for the optimization problem [62].

Zhang et al. [63] applied Election Campaign Optimization (ECO) to design the pressure vessel. The objective of the problem is to minimize the total cost of the material, forming and welding of a cylindrical vessel. There are four design variables thickness of the shell, thickness of the head, the inner radius and length of the cylindrical section of the vessel. The results show that ECO algorithm can be used to search out the optimal solutions of the optimization design problem.

\subsection{Anarchic society optimization}

Ahmadi-Javid [64] introduced the Anarchic Society Optimization (ASO) algorithm which is based on humaninspired swarm intelligence optimization. Anarchic is acquired from the Greek word "Anarkos" meaning 'no chief' and "Anarchia" means 'lack of authority'. In this algorithm the members are animated as an anarchic society and act audaciously to seek out improved situations. As their situations deteriorate and therefore the dissimilarities among them aggravate the members are volatile and become more anarchic and unforeseeable. During this method, each individual is selected for its next position, consistent with the personal experiences and group or association incidents. To end, the group of members try to get a near-optimal solution after several actions. The proposed ASO algorithm [65] has applied successfully in many areas and it gives better results.

Production planning and control functions allocate limited available resources. Manufacturing environment resources are machines, material handling equipment, and employees. Ahmadi-Javid et.al [66] integrated and optimized employee timetabling into the scheduling of machines and transporters in a job-shop environment. The objective is to minimize the completion time of all jobs. Anarchic Society Optimization algorithm was applied for optimization.

\subsection{Teaching learning-based algorithm}

The Teaching Learning-based algorithm (TLBO) was proposed by Zou et al. [67]. This algorithm follows the population - based searching stochastic methodology. The encouragement by the teachers to the learners reflects in the form of final solution. It animates the ideology of the teachinglearning process during a classroom and imitates the effect of an educator on the learners. The TLBO algorithm is basically divided into two parts. The primary part comprises of the 'Teacher phase' and the second part comprises of the 'Learner phase'. The 'Teacher phase' shows the training from the teacher and the 'Learner phase' shows the training from the interaction between learners. In each of the training phase learners are interested in an optimal global solution [68].

Rao et al. [69] proposed another efficient optimization technique called Teaching Learning Based Optimization (TLBO) algorithm. They applied it to many mechanical domain problems as design of a pressure vessel. The objective was to minimize the total cost of a pressure vessel considering the cost of material, forming and welding. The second problem was design of tension/compression spring. The objective is to minimize the weight of a tension/compression spring subjected to one linear and three nonlinear inequality constraints. Third problem defined was design of welded beam. The objective is to design a welded beam for minimum cost. There are four continuous design variables with two linear and five nonlinear inequality constraints. Last problem was design of gear train. The objective is to minimize the weight of a gear train with one discrete and six continuous design variables. There are four linear and seven nonlinear inequality 
constraints. Constrained mechanical engineering problems were optimizing the mass of Multiple disc clutch brake, design of robot gripper, design of step cone pulley etc. Effectiveness of TLBO has been proved with many other algorithms from literature for these classical problems, which have been already attempted by many researchers.

Sleesongsom et al. [70] proposed new version of Teaching Learning Based Optimization (TLBO) algorithm termed as Self-Adaptive Population Size Teaching Learning Based Optimization. Four-bar linkage mechanisms are found commonly in mechanical engineering and manufacturing domain. An optimization problem with an objective function to minimize the error between targeted and obtained coupler curves in mechanism has been formed. The results indicate that the new optimizer outperforms the original TLBO in solving all engineering application problems.

Thamaraikanna et al. [71] demonstrated their work on mechanical components utilizing Teaching Learning Based Optimization (TLBO) with a differential operator. Three typical optimization problems are considered in this research: firstly, to optimize the weight in a belt-pulley drive, secondly, to optimize the volume in a closed coil helical spring, and finally to optimize the weight in a hollow shaft. Simulation result on the optimization (mechanical components) problems reveals the ability of the proposed methodology to find better optimal solutions compared to other optimization algorithms.

Weld joint quality depends on the welding parameters applied the process, which defined in terms of weld bead geometry. Selection of proper parameters is very crucial. Jogi et al. [72] optimized parameters for Metal Inert Gas (MIG) welding on AISI 1018 mild steel by Teaching-Learning Based Optimization (TLBO) Algorithm. The process parameters considered are welding current, workpiece thickness, voltage and wire feed rate. Mathematical models are developed for weld reinforcement $(\mathrm{BH})$, weld penetration $(\mathrm{BP})$ and bead width (BW). TLBO algorithm effectively handled the mathematical models and parameters optimized for MIG welding process with less computational efforts.

Farshchin et al. [73] presented a Multi-Class Teaching Learning Based Optimization (MC-TLBO) system. The idea is to extend the concept of the education process from a single classroom to a school with multiple simultaneous classes. It was applied to the size and shape optimization of truss for structural weight under frequency constraints. Optimization results show that MC-TLBO generates efficient low-cost designs. From statistical point of view, the proposed algorithm is more computationally robust and efficient than other techniques.

Additive manufacturing process represents new class of manufacturing called as additive manufacturing. It has totally changed the approach the way prototypes were being manufactured. The complexity of product, innovative configurations tools and dies can be easily manufactured without depending on skill of worker. Rao et al. [74] optimized Fused Deposition Modeling (FDM) process utilizing the Teaching Learning Based Optimization (TLBO). Different case studies were presented. The first one relates with prediction of compressive strength of the FDM model. The process parameters studied were layer thickness $(\mathrm{mm})$, orientation (degree), raster angle (degree), raster width (mm) and air gap $(\mathrm{mm})$. The second for predicting the sliding wear $\left(\mathrm{mm}^{3} / \mathrm{m}\right)$ of the models built by the FDM process. The process parameters are layer thickness $(\mathrm{mm})$, part-built orientation (degree), raster angle (degree), raster width ( $\mathrm{mm}$ ) and air gap.
The third case study has objective to optimize built dimensional errors, wrap deformation and build time. The process parameters studied were line width compensation $(\mathrm{mm})$, extrusion velocity $(\mathrm{mm} / \mathrm{s})$, filling velocity $(\mathrm{mm} / \mathrm{s})$, layer thickness $(\mathrm{mm})$. Another case study considers mechanical properties such as tensile strength (MPa), flexural strength $(\mathrm{MPa})$ and impact strength $(\mathrm{MPa})$ of the models fabricated using the FDM process with the process parameters such as layer thickness ( $\mathrm{mm}$ ), orientation (degree), raster angle (degree), raster width ( $\mathrm{mm})$, air gap $(\mathrm{mm})$. The research work compares the results obtained by TLBO and that of Genetic Algorithm and quantum behaved particle swarm optimization (QPSO) algorithm. The TLBO algorithm showed better performance as compared to GA and QPSO algorithms. The non-dominated sorting TLBO algorithm proposed to solve the multi- objective optimization problems of the FDM process in this work is a posteriori version of the TLBO algorithm.

\subsection{Cultural evolution algorithm}

In today's era, the culture could be figuratively programmed and communicated between different traditional mechanism. To support this, Ma et al. [75] proposed a cultural evolution algorithm (CEA) during which cultural evolution is seen over years. The cultural evolution works on clear directions. The common goal of all the cultures is to achieve a higher spiritual state which is referred as optimum state. The CEA is furnished with a concept of collective intelligence. The algorithm uses the primitive information and defines the initial cultural form for species [76]. Then it improves the cultural species via evolution and finally attains the spiritual state. Here cultural species are referred as solutions and higher state is referred as optimum solution [77].

Yan et al. [78] worked on engineering design problems using a Cultural Evolution Algorithm (CEA). The paper presents four constrained engineering design problems; first one is design of tension/compression spring, design of pressure vessel issue, third is design of welded beam and fourth is satellite costs. The results obtained are encouraging and proves its efficiency for mechanical engineering problems.

Yuan et al. [79] had demonstrated work on scheduling of hydrothermal power plant utilizing Cultural Algorithm. Generation and utilization of electricity is very vital for economy and security. The scheduling of thermal system is a large scale dynamic non-linear constrained optimization problem. The objective is to find the water release from each reservoir and the corresponding unit thermal energy generation. With minimizing the total cost of fuel for thermal generation while satisfying diverse hydraulic, thermal and load balance constraints.

\subsection{Cohort intelligence algorithm}

This algorithm mimicked the self-managed learning behavior of group candidates. So, supporting this concept Kulkarni et al. [80] introduced Cohort Intelligence (CI) algorithm. The cohort advice to a group of candidates to collaborate and interact with each individual to accomplish personal goals which are shared with all. In each learning stage, candidate modifies its behavior to understand some qualities from other candidates. Cohort intelligence was found useful for solving large-sized problems with application to mesh smoothing of complex geometry [81], spring back optimization in metal forming [82], design and economic 
optimization of shell and tube device and minimization of clearance variation of a Radial Selective Assembly problems in mechanical domain [83].

Kulkarni et al. [82] had worked on the Cohort Intelligence (CI) algorithm. The proposed work was extension of Cohort Intelligence (CI) Algorithm for constrained problems. The paper presented the use of static penalty approach and the dynamic penalty approach to convert the constrained problems to unconstrained problems and solve by using CI algorithm. The paper presented the validation of the static penalty using cohort intelligence (SCI) and dynamic penalty using cohort intelligence (DCI) on the benchmark problems. The paper also presented the effective use of SCI and DCI in the mechanical engineering real-life problem of thinning in automotive part called connector, spring back in punch plate, thickening in tail cap. The results obtained in the paper for the application in mechanical problem showed the performance of DCI was better than the SCI.

Dhavle et al. [84] had worked on the Cohort Intelligence (CI) algorithm. The paper presented enhancement of shell and tube heat exchanger [STHE] with three cases. The several costs associated with the STHE are the capital investment cost, annual operating cost, energy cost and total discounted operating cost $\mathrm{d}$. The objective function is to minimize the total cost. The CI solutions were found to be better than other algorithms as Genetic Algorithm, Particle Swarm Optimization etc.

Sapre et al. [85] had attempted for mesh quality improvement using Cohort Intelligence (CI) Algorithm. Finite element analysis has proved to be best tool for assessment of designs prior actual manufacturing. Ansys was used for experimentation. The ultimate aim of research was summation of condition numbers of all elements. The geometrical boundaries of the object defined the surface and edge constraints for movement of external nodes. The CI was varied for studying movements of internal nodes using roulette wheel [86], follow best, follow better, alienation and random selection, follow worst and follow itself. The geometries applied were pentagonal prism, hexagonal prism and hexagonal prism with hole.

Variability and interchangeability are vital parts of manufacturing. The mating parts are called as male and female parts, tolerances play a major role in assembly. The mass production is fully based on concept of interchangeability. Selective assembly is a cost-effective approach to attaining necessary clearance variation in the resultant assembled product from the low precision elements. Nair et al. [87] studied selective assembly. The objective function is to optimize clearance variance. The CI was adopted with roulette wheel and without roulette wheel. MATLAB R2016b was utilized to code and run the calculation. It was also observed that on increasing the number of candidates, premature convergence is avoided, thus resulting in better outputs showing the robustness of CI algorithm.

\subsection{Soccer league competition algorithm}

Moosavian et al. [88] introduced a new meta-heuristic approach, known as The Soccer League Competition (SLC) algorithm. The fundamental ideas and concepts of the tactic are inspired by soccer leagues and supported competitions among teams and players. The simplest solution is named superstar player (SSP) and every solution is named player. Each player is divided into few teams. The competition between teams controls the top-ranked position within the league table, and therefore the competition between players in each team for personal improvement. Replacement occurs in few teams with new ones if there has been no improvement in their most suitable options during the optimization process. This replacement procedure is completed to flee the algorithm from local minimum and highlands [89].

Sizing optimization of truss structures is one of the discrete optimization problems which has been attempted by many meta-heuristic algorithms. Optimization of truss structures includes choosing the best cross-sections for the truss members, which in turn minimize the structural weight in order to satisfy inequality stress and displacement constraints that limit design variable sizes. Moosavian [90] applied Soccer League Competition Algorithm for solving the same problem and its performance with other optimizers has been compared using statistical analysis. Other researchers have applied Particle Swarm Optimization, Ant Colony Optimization algorithms, Big Bang-Big Crunch algorithm and Particle Swarm Ant Colony Optimization, Artificial Bee Colony, Mine Blast algorithm, Colliding Bodies algorithm, Flower Pollination algorithm, Adaptive Dimensional Search, Search Group algorithm, have improved the minimum weight of truss structures.

\subsection{Election algorithm}

The Election Algorithm (EA) was proposed by Emami and Derakshan [91]. The EA is a continual population-based algorithm, it deals with the population which are a set of solutions, mimicking the election process in the real world. This algorithm also called multi-agent algorithm during which, each agent is a person and may be either a candidate or a voter (supporters) from some political party. At the initial stage of the algorithm, all supporters are divided among candidates based on their similar opinions and ideas. After initial slots, a candidate begins his/her advertising campaign in each party. Advertising campaign contains three types of advertisements including positive, negative and combined advertisement. During the election, candidates bear their agendas and thoughts to the voters and try to fascinate voters towards themselves. This strategy is known as a positive advertisement. In the negative advertisement, each candidate increases their own popularity and decrease the popularity of opposition candidates. In the result of the election, the negative advertisement makes an important effect. During the advertising campaign, the candidates that have the same opinions and agendas might tie and make a new party which is a combination of these parties. At the end of the algorithm, the candidate who achieved more votes will be announced as the winner. The winner candidate makes equal to the best solution found for the optimization and search problems [92].

\subsection{Social learning optimization}

Liu et al. [93] and Gong et al. [94] proposed the social learning optimization algorithm [SLO]. This algorithm was encouraged by the social learning theory and the development process of human intelligence. The SLO has three types of spaces: the ground is micro-space; the center layer is that the learning space, the assumption space which is extracted from the center layer and delivered to the highest layer. Nowadays, observation learning theory starts progressing in human society. So, this theory is widely useful in the area of 
psychology and praxeology. This observational learning theory consists of four events: attention, retention, reproduction and motivation. These operators prove the algorithm very simple. By the process to improve the fitness value of the people it is possible by comparing the natural evolution process with the previous stage. During this sense, the proposed algorithm has probable to improve the efficiency of the algorithms [95].

\subsection{Social group optimization}

There are several qualities like morality, gentle, kindness, courage, fairness, anxiety and honors etc., which require to be hooked up and to be channelized within the appropriate direction to change him/her to resolve complicated tasks in life. Few people might need the level of these activity qualities to be practiced at higher level to tackle complicated issues in life. However, complicated issues are often resolved by discrimination of qualities from one person to different or from one cluster to different teams within society. Supporting this idea, a new optimization methodology is projected by Satapathy et al. [96] known as Social Group Optimization (SGO). The strategy of SGO [97] is split into two components. The primary half involves the 'improving phase' and the second half contains the 'acquiring phase'. In 'improving phase', the information level of every person within the cluster is improved with the impact of the most effective person within the cluster. The most effective person within the cluster is one having the very best level of data and capability to resolve the matter. In second section that is 'acquiring phase', everybody enhances their information with the mutual interaction with another person within the cluster and therefore, the best person within the cluster at that time in time [98].

Madhavi et al. [99] applied Social Group Optimization (SGO) for economic load dispatch (ELD) problem of power generating units. The performance of the proposed algorithm is investigated and tested with two standard test systems, the IEEE 14 bus with five units, IEEE 30 bus with 6 units and IEEE 57 bus with 7 units. The results obtained were quite encouraging when compared with PSO.

\subsection{Ideology algorithm}

Huan et al. [100] introduced a novel algorithm which is referred to as Ideology Algorithm (IA). It is stimulated via modest behavior of the political party and the self-confidence. Based on this behavior, people feeding themselves to improve their ranking. In the proposed algorithm, all members join with the party, because the party have a perfect solution search space. The top position of the party is decided through the quality solution. The candidate who secures the best solution in the party is considered as a leader of the local party and the candidate wins among the all local party leader is called to be the global leader or global solution space. The party leader continues improving his better solution by collaborating with another best party.

\section{CONCLUSION}

The paper thoroughly discusses application of social cultural inspired algorithms for mechanical engineering applications. It has been observed that thermal engineering and energy engineering domain has been successfully explored for application of these algorithms. Energy analysis, exergy analysis, design of heat exchanger, economic load dispatch in load units etc. were attempted. Typical design optimization of components as springs, trusses, welded joints, pressure vessels, weight in a belt-pulley drive, helical springs, hollow shafts, four bar mechanism as well as speed reducer has been successfully carried out. There are certain innovative applications as in material science involving optimum combination of material for metal matrix composites. The second one is mesh quality improvements in finite element analysis.

The manufacturing domain has been explored but more on system side than processes. Only metal forming and additive manufacturing optimization has been observed. Production planning and control, distribution of facilities, production layout optimization, variability and interchangeability in assembly. There is more scope to apply it for optimization of traditional and advanced manufacturing processes. It is obvious from results that, all these algorithms have shown very encouraging results as compared to other optimizers. It can be concluded that these algorithms can be applied to other areas of mechanical engineering also.

\section{REFERENCES}

[1] Michalewicz, Z., Attia, N.F. (1994). Evolutionary optimization of constrained problems. Proceedings of the 3rd annual conference on evolutionary programming; Singapore: World Scientific, pp. 98-108. https://dx.doi.org/10.1007/978-3-540-39883-7_3

[2] Zedadra, Z., Guerrieri, A., Jouandeau, N., Spezzano, G., Seridi, H., Fortino, G. (2018). Swarm intelligence-based algorithms within IoT-based systems: A review. Journal of Parallel Distributed Computing, 122: 173-187. https://doi.org/10.1016/j.jpdc.2018.08.007

[3] Zhao, X.C. (2010). A perturbed particle swarm algorithm for numerical optimization. Journal of Applied Soft Computing, 10 : 119-124. https//doi.org/10.1016/j.asoc.2009.06.010

[4] Kulkarni, N.K., Patekar, S., Bhoskar, T., Kulkarni, O., Kakandikar, G.M., Nandedkar, V.M. (2015). Particle swarm optimization applications to mechanical engineering-a review. Materials Today: Proceedings, 2(4-5): https://doi.org/10.1016/j.matpr.2015.07.223

[5] Rajabioun, R. (2011). Cuckoo optimization algorithm. Journal of Applied Soft Computing, 11: 5508-5518. https://doi.org/10.1016/j.asoc.2011.05.008

[6] Joshi, A.S., Kulkarni, O., Kakandikar, G.M., Nandedkar, V.M. (2017). Cuckoo search optimization-a review. Materials Today: Proceedings, 4: 7262-7269. https://doi.org/10.1016/j.matpr.2017.07.055

[7] Mirjalili, S., Mirjalili, S.M., Lewis, A. (2014). Grey wolf optimizer. Advances in Engineering Software, 69: 46-61. http://dx.doi.org/10.1016/j.advengsoft.2013.12.007

[8] Kulkarni, O., Kulkarni, S. (2018). Process parameter optimization in WEDM by grey wolf optimizer. Materials Today: Proceedings, 5(2): 4402-4412. https://doi.org/10.1016/j.matpr.2017.12.008

[9] Akbari, R., Hedayatzadeh, R., Ziarati, K., Hassanizadeh, B. (2012). A multi-objective artificial bee colony algorithm. Journal of Swarm and Evolutionary Computation,

2: 39-52. 
https://doi.org/10.1016/j.swevo.2011.08.001

[10] Yang, X.S., He, X.S. (2013). Firefly algorithm: Recent advances and applications. International Journal of Swarm Intelligence, $1(1)$ : $36-50$. https://doi.org/10.1504/IJSI.2013.055801

[11] Blum, C. (2005). Ant colony optimization: Introduction and recent trends. Journal of Physics of Life Reviews, 2: 353-373. https://doi.org/10.1016/j.plrev.2005.10.001

[12] Guo, L., Meng, Z., Sun, Y.Z., Wang, L.B. (2016). Parameter identification and sensitivity analysis of solar cell models with cat swarm optimization algorithm. Journal of Energy Conversion and Management, 108: 520-528.

http://doi.org/10.1016/j.enconman.2015.11.041

[13] Kashi, S., Minuchehr, A., Poursalehi, N., Zolfaghari, A. (2014). Bat algorithm for the fuel arrangement optimization of reactor core. Journal of Annals of Nuclear Energy, 64: 144-151. https://doi.org/10.1016/j.anucene.2013.09.044

[14] Tsallis, C., Stariolo, D.A. (1996). Generalized simulated annealing. Journal of Physica A, 233: 395-406. https://doi.org/10.1016/s0040-6090(02)01134-3

[15] Zuccolotto, M., Pereira, C.E. (2015). Designing an artificial immune system for intelligent maintenance systems. International Federation of Automatic Control Papers Online, 48(3): 1451-1456. https://doi.org/10.1016/j.ifacol.2015.06.291

[16] Meliani, Y., Hani, Y., Elhaq, S.L. (2019). A developed Tabu search algorithm for heterogeneous fleet vehicle routing problem. International Federation of Automatic Control Papers Online, 52(13): 1051-1056. https://doi.org/10.1016/j.ifacol.2019.11.334

[17] Mahaleh, M.B.B., Mirroshandel, S.A. (2018). Harmony search path detection for vision-based automated guided vehicle. Journal of Robotics and Autonomous Systems. 107:

156-166 https://doi.org/10.1016/j.robot.2018.06.008

[18] Liu, Q., Ren, H.P., Tang, R.J., Yao, J.L. (2019). Optimizing co-existing multicast routing trees in IP network via discrete artificial fish school algorithm. Journal of Knowledge-Based Systems, 191: 105276. https://doi.org/10.1016/j.knosys.2019.105276

[19] Xie, X.F., Zhang, W.J., Yang, Z.L. (2002). Social cognitive optimization for nonlinear programming problems. Proceedings of the First International Conference on Machine Learning and Cybernetics, Beijing, pp. $779-783$ https://doi.org/10.1109/ICMLC.2002.1174487

[20] Jiang, Y.Z., Yeh, W.C., Hao, Z.F., Yang, Z.L. (2016). A cooperative honey bee mating algorithm and its application in multi-threshold image segmentation. Journal of Information Sciences, 369: 171-183. https://doi.org/10.1016/j.ins.2016.06.020

[21] Han, X.H., Chang X.M. (2014). Feature subset selection by gravitational search algorithm optimization. Journal of Information Sciences, 281: 128-146. https://doi.org/10.1016/j.ins.2014.05.030

[22] Rao, B.V., Kumar, G.V.N. (2015). Optimal power flow by BAT search algorithm for generation reallocation with unified power flow controller. Journal of Electrical Power and Energy Systems, 68: 81-88. https://doi.org/10.1016/j.ijepes.2014.12.057

[23] Abdelaziz, A.Y., Ali, E.S., Elazim, S.M.A. (2016). Combined economic and emission dispatch solution using Flower Pollination Algorithm. Journal of Electrical Power and Energy Systems, 80: 264-274. https://doi.org/10.1016/j.ijepes.2015.11.093

[24] Yu, J.J.Q., Li, V.O.K. (2015). A social spider algorithm for global optimization. Journal of Applied Soft Computing Journal, 30: 614-627. https://doi.org/10.1016/j.asoc.2015.02.014

[25] Astudillo, L., Melin, P., Castillo, O. (2014). Introduction to an optimization algorithm based on the chemical reactions. Information Sciences, 291: 85-95. https://doi.org/10.1016/j.ins.2014.08.043

[26] Findik, O. (2015). Bull optimization algorithm based on genetic operators for continuous optimization problems. Turkish Journal of Electrical Engineering \& Computer Science, 23: 2225-2239. https://doi.org/10.3906/elk1307-123

[27] Elhosseini, A.M., Sehiemy, R.A.E, Rashwan, Y.I., Gao, X.Z. (2019). On the performance improvement of elephant herding optimization algorithm. Journal of Knowledge-Based Systems, 166: 58-70. https://doi.org/10.1016/j.knosys.2018.12.012

[28] Mirjalili, S., Lewis, A. (2016). The whale optimization algorithm. Journal of Advances in Engineering Software, 95: 51-67. https://doi.org/10.1016/j.advengsoft.2016.01.008

[29] Wu, Z., Yu, D.Q., Kang, X.H. (2017). Parameter identification of photovoltaic cell model based on improved ant lion optimizer. Journal of Energy Conversion and Management, 151: 107-115. https://doi.org/10.1016/j.enconman.2017.08.088

[30] Mirjalili, S. (2015). Moth-flame optimization algorithm: A novel nature-inspired heuristic paradigm. Journal of Knowledge-Based Systems, 89: 228-249. https://doi.org/10.1016/j.knosys.2015.07.006

[31] Li, S., Fang, H.J., Liu, X.Y. (2017). Parameter optimization of support vector regression based on sine cosine algorithm. Journal of Expert Systems with Applications, $\quad$ 91: 63-77. https://doi.org/10.1016/j.eswa.2017.08.038

[32] Guha, D., Roy, P.K., Banerjee, S. (2018). Optimal tuning of 3 degree-of-freedom proportional-integral-derivative controller for hybrid distributed power system using dragonfly algorithm. Journal of Computers and Electrical Engineering, 72: 137-153. https://doi.org/10.1016/j.compeleceng.2018.09.003

[33] Mirjalili, S., Gandomi, A.H., Mirjalili, S.Z., Saremi, S., Faris, H., Mirjalili, S.M. (2017). Salp swarm algorithm: A bio-inspired optimizer for engineering design problems. Journal of Advances in Engineering Software, 114: $1-29$. https://doi.org/10.1016/j.advengsoft.2017.07.002

[34] Mhatugade, S.P., Kakandikar, G.M, Kulkarni O.K., Nandedkar, V.M. (2019). Development of a multiobjective salp swarm algorithm for benchmark functions and real-world problems. ISTE Ltd and John Wiley \& Sons, Inc, Optimization for Engineering Problems.

[35] Saremi, S., Mirjalili, S., Lewis, A. (2017). Grasshopper optimization algorithm: Theory and application. Journal of Advances in Engineering Software, 105: 30-47. https://doi.org/10.1016/j.advengsoft.2017.01.004

[36] Neve, A.G., Kakandikar G.M., Kulkarni, O. (2017). Application of grasshopper optimization algorithm for constrained and unconstrained test functions. International Journal of Swarm Intelligence and 
Evolutionary Computation, 105: 30-47. https://doi.org/10.1016/j.advengsoft.2017.01.004

[37] Mitchell, M. (1996). An Introduction to Genetic Algorithms. MIT Press, London, UK.

[38] Bhoskar, T., Kulkarni, O.K., Kulkarni, N.K, Patekar, S.L., Kakandikar, G.M., Nandedkar, V.M. (2015). Genetic algorithm and its applications to mechanical engineering: A review. Journal of Materials Today: Proceedings, 2(4-5): 2624-2630. https://doi.org/10.1016/j.matpr.2015.07.219

[39] Mallipeddi, R.M., Lee, M. (2015). An evolving surrogate model-based differential evolution algorithm. Journal of Applied Soft Computing, 34: 770-787. https://doi.org/10.1016/j.asoc.2015.06.010

[40] Kumar, M., Kulkarni, A.J., Satapathy, S.C. (2017). Socio evolution \& learning optimization algorithm: A socioinspired optimization methodology. Journal of Future Generation Computer Systems, 81: 252-272. https://doi.org/10.1016/j.future.2017.10.052

[41] Chikha, M.A.A, Belaidia, I. (2018). Efficiency of bioand socio-inspired optimization algorithms for axial turbo-machinery design. Journal of Applied Soft Computing, 64: 282-306. https://doi.org/10.1016/j.asoc.2017.11.048

[42] Ray T., Liew, K.M. (2003). Society and civilization: An optimization algorithm based on the simulation of social behavior. IEEE Transactions on Evolutionary Computation, $7(4)$. https://doi.org/10.1109/TEVC.2003.814902

[43] Xing, B., Gao, W.J. (2014). Imperialist competitive algorithm. International Publishing Switzerl Intelligent Systems Reference Library 62.

[44] Hosseini, S., Khaled, A.A. (2014). A survey on the mperialist Competitive Algorithm metaheuristic: Implementation in engineering domain and directions for future research. Journal of Applied Soft Computing, 24: 1078-1094. https://doi,org/10.1016/j.asoc.2014.08.024

[45] Lucas, C., Nasiri-Gheidari, Z., Tootoonchian, F. (2010). Application of an imperialist competitive algorithm to the design of a linear induction motor. Journal of Energy Conversion Manage, 51(7): 1407-1411. https://doi.org/10.1016/j.enconman.2010.01.014

[46] Niknam, T., Fard, E.T., N., Pourjafarian, N. (2011). An efficient hybrid algorithm based on modified imperialist competitive algorithm and K-means for data clustering. Journal of Engineering Application Artificial Intelligence, 24(2): 306-317. https://doi.org/10.1016/j.engappai.2010.10.001

[47] Nazari-Shirkouhi, S., Eivazy, H., Ghodsi, R., Rezaie, K., Atashpaz-Gargari, E. (2010). Solving the integrated product mix-outsourcing problem using the imperialist competitive algorithm. Journal of Expert System Application, $\quad 37(12)$ : 7615-7626. https://doi.org/10.1016/j.eswa.2010.04.081

[48] Pan, Z.X., Lei, D.M., Zhang, Q.Y. (2018). A new imperialist competitive algorithm for multi-objective low carbon parallel machines scheduling. Hindawi Mathematical Problems in Engineering, 2018: 1-13.

[49] Nourmohammadi, A., Zandieh, M., TavakkoliMoghaddam, R. (2013). An imperialist competitive algorithm for multi-objective U-type assembly line design. Journal of Computational Science, 4: 393-400. https://doi.org/10.1016/j.jocs.2012.09.001

[50] Bayareh, M., Mohammadi, M. (2016). Multi-objective optimization of a triple shaft gas compressor station using Imperialist Competitive Algorithm. The Journal of Applied Thermal Engineering, 109: 384-400. https://doi.org/10.1016/j.applthermaleng.2016.08.089

[51] Hadidi, A., Hadidi, M., Nazari, A. (2013). A new design approach for shell-and-tube heat exchangers using imperialist competitive algorithm (ICA) from economic point of view. Energy Conversion and Management, 67: 66-74. https://doi.org/10.1016/j.enconman.2012.11.017

[52] Sinnot, R.K. (2005). Coulson Richardson's.Chemical engineering design. Elsevier's Science \& Technology, vol. 6., Butterworth-Heinemann.

[53] Kern D.Q. (1950). Process Heat Transfer. McGraw-Hill International Book Company.

[54] Karami, A., Rezaei, E., Shahhosseni, M., Aghakhani, M. (2012). Optimization of heat transfer in an air cooler equipped with classic twisted tape inserts using imperialist competitive algorithm. The Journal of Experimental Thermal and Fluid Science, 38: 195-200. https://doi.org/10.1016/j.expthermflusci.2011.12.007

[55] Yousefi, M., Darus, A.N., Mohammadi, H. (2012). An imperialist competitive algorithm for optimal design of plate-fin heat exchangers. International Journal of Heat and Mass Transfer, 55: 3178-3185. https://doi.org/10.1016/j.ijheatmasstransfer.2012.02.041

[56] Rezaei, H., Bozorg-Haddad, O., Chu, X.F. (2017). League championship algorithm. Journal of Advanced Optimization by Nature-Inspired Algorithms, Studies in Computational Intelligence, 720: 19-30. https://doi.org/10.1007/978-981-10-5221-7_3

[57] Abdulhamid, S.M., Latiff, M.S.A., Madni, S.H.H., Oluwafemi, O. (2015). A survey of league championship algorithm: Prospects and challenges. Indian Journal of Science and Technology, 8(S3): 101-110. https://doi.org/10.17485/ijst/2015/v8iS3/60476

[58] Kashan, A.H. (2011). An efficient algorithm for constrained global optimization and application to mechanical engineering design: League championship algorithm (LCA). The Journal of Computer-Aided Design, $\quad 43$ : 1769-1792. https://doi.org/10.1016/j.cad.2011.07.003

[59] Kumar, R.P., Periyasamy, P, Rangarajan, S., Sathish, T. (2020). League championship optimization for the parameter selection for $\mathrm{Mg} / \mathrm{WC}$ metal matrix composition. Materials Today: Proceedings, 21(Part 1): 504-510. https://doi.org/10.1016/j.matpr.2019.06.646

[60] Xu, G.X., Li, W.F., Liu, J. (2020). A social emotion classification approach using multi-model fusion. Journal of Future Generation Computer Systems, 102: 347-356. https://doi.org/10.1016/j.future.2019.07.007

[61] Lv, W.G., Xie, Q.H., Liu, Z.Y., Zhang, X.W., Luo, S.M., Cheng, S.Y. (2010). Election campaign algorithm. 2010 2nd International Asia Conference on Informatics in Control, Automation and Robotics (CAR 2010), Wuhan, pp. 71-74. https://doi.org/10.1109/CAR.2010.5456623.

[62] Lv, W.G., He, C.H., Li, D.Y., Cheng, S.Y., Luo, S.M., Zhang, X.W. (2012). Election campaign optimization algorithm. International Conference on Computational Science, ICCS 2010, Procedia Computer Science, 1: 1377-1386. https://doi.org/10.1016/j.procs.2010.04.153

[63] Zhang, H., Lv, W.G., Cheng, S.Y., Luo, S.M., Zhang, X.W. (2011). Election campaign optimization algorithm for design of pressure vessel. The Journal of Advanced Materials Research, 308-310: 15-20. 
[64] Ahmadi-Javid, A. (2011). Anarchic society optimization: A human-inspired method. 2011 IEEE Congress of Evolutionary Computation (CEC), pp. 2586-2592. https://doi.org/10.1109/CEC.2011.5949940

[65] Bozorgi, A., Bozorg-Haddad, O., Chu, X.F. (2018) Anarchic Society Optimization (ASO) Algorithm. Journal of Advanced Optimization by Nature-Inspired Algorithms. Studies in Computational Intelligence, 720.

[66] Ahmadi-Javid, A., Hooshangi-Tabrizi, P. Integrating employee timetabling with scheduling of machines and transporters in a job-shop environment: A mathematical formulation and an Anarchic Society Optimization algorithm. The Journal of Computers and Operations Research, 84: 73-91. https://doi.org/10.1016/1016/j.cor.2016.11.017

[67] Zou, F., Chen, D.B., Xu, Q.Z. (2018). A survey of teaching-learning-based optimization. Neurocomputing, 335: https://doi.org/10.1016/j.neucom.2018.06.076

[68] Shukla, A.K., Singh, P., Vardhan, M. (2020). An adaptive inertia weight teaching-learning-based optimization algorithm and its applications. The Journal of Applied Mathematical Modelling, 77: 309-326. https://doi.org/1016/j.apm.2019.07.046

[69] Rao, R.V., Savsani, V.J., Vakharia, D.P. (2011). Teaching-learning-based optimization: A novel method for constrained mechanical design optimization problems. The Journal of Computer-Aided Design, 43: 303-315. https://doi.org/10.1016/j.cad.2010.12.015

[70] Sleesongsom, S., Bureerat, S. (2017). Four-bar linkage path generation through self-adaptive population size teaching-learning based optimization. Knowledge-Based Systems, 135: 180-191. https://doi.org/10.1016/j.knosys.2017.08.012

[71] Thamaraikannan, B., Thirunavukkarasu, V. (2014). Design optimization of mechanical components using an enhanced teaching-learning based optimization algorithm with differential operator. Hindawi Publishing Corporation Mathematical Problems in Engineering 2014: 1-10.

[72] Jogi, B.F., Awale, A.S., Nirantar, S.R., Bhusare, H.S. (2018). Metal Inert Gas (MIG) Welding Process Optimization using Teaching-Learning Based Optimization (TLBO) Algorithm. Materials Today: Proceedings, 5(2): 7086-7095. https://doi.org/10.1016/j.matpr.2017.11.373

[73] Farshchin, M., Camp, C.V., Maniat, M. (2016). Multiclass teaching-learning-based optimization for truss design with frequency constraints. The Journal of Engineering Structures, 106: 355-369. https://doi.org/10.1016/j.engstruct.2015.10.039

[74] Rao, R.V., Rai, D.P. (2016). Optimization of fused deposition modeling process using teaching learningbased optimization algorithm. Engineering Science and Technology, an International Journal, 19: 587-603. https://doi.org/10.1016/j.jestch.2015.09.008

[75] Ma, J, Zhang, J.P., Yang, J., Cheng, L.L. (2008). Research on cultural algorithm for solving routing problem of mobile agent. The Journal of China Universities of Posts and Telecommunications, 15(4): 121-125. https://doi.org/10.1016/S1005-8885(08)60415$\mathrm{X}$

[76] Kuo, H.C., Lin, C.H. (2013). Cultural evolution algorithm for global optimizations and its applications.
The Journal of Applied Research and Technology, 11(4): 510-522. https://doi.org/10.1016/S1665-6423(13)71558$\mathrm{X}$

[77] Yuan, X.H., Yuan, Y.B. (2006). Application of cultural algorithm to generation scheduling of hydrothermal systems. The Journal of Energy Conversion and Management, 47: 2192-2201. https://doi.org/10.1016/j.enconman.2005.12.006

[78] Yan, X.S., Li, W., Chen, W., Luo, W.J., Zhang, C., Liu, H. (2012). Cultural algorithm for engineering design problems. IJCSI International Journal of Computer Science Issues, 9(6): 53-61.

[79] Yuan, X.H., Yuan, Y.B. (2006). Application of cultural algorithm to generation scheduling of hydrothermal systems. The Journal of Energy Conversion and Management, $\quad 47$ : 2192-2201. https://doi.org/10.1016/j.enconman.2005.12.006

[80] Kulkarni, A.J., Krishnasamy, G., Abraham, A. (2017). Cohort intelligence: A socio-inspired optimization method. Intelligent Systems Reference Library, Springer International Publishing, Switzerland.

[81] Kulkarni, N., Kulkarni, A.J., Kakandikar, G. (2016). Constrained cohort intelligence using static and dynamic penalty function approach for mechanical components design. International Journal of Parallel, Emergent and Distributed Systems.

[82] Kulkarni, O., Kakandikar, G.M. (2015). Spring back optimization in metal forming using cohort intelligence. International Engineering Research Journal (IERJ) Special Issue, 2: 2938-2942.

[83] Kale, I.R., Kulkarni, A.J. (2017). Cohort intelligence algorithm for discrete and mixed variable engineering problems. International Journal of Parallel, Emergent and Distributed Systems, 33(6): 627-662. https://doi.org/10.1080/17445760.2017.1331439

[84] Dhavle, S.V., Kulkarni, A.J., Shastri, A., Kale, I.R. (2016). Design and economic optimization of shell and tube heat exchanger using cohort intelligence algorithm. The Natural Computing Applications Forum.

[85] Sapre, M.S., Kulkarni, A.J., Chettiar, L., Deshpande, I., Piprikar, B. (2018). Mesh smoothing of complex geometry using variations of cohort intelligence algorithm. Evolutionary Intelligence, Springer-Verlag GmbH Germany, part of Springer Nature.

[86] Lipowski, A., Lipowska, D. (2012). Roulette-wheel selection via stochastic acceptance. The Journal of Physica A, 391: 2193-2196. https://doi.org/10.1016/j.physa.2011.12.004

[87] Nair, V.H., Acharya, V., Dhavle, S.V., Shastri, A.S., Patel, J. Minimization of clearance variation of a radial selective assembly using cohort intelligence algorithm. Proceedings of the 2nd International Conference on Data Engineering and Communication Technology, pp. 165173. https://doi.org/10.1007/978-981-13-1610-4_17

[88] Moosavian, N., Roodsari, B.K. (2014). Soccer league competition algorithm: A novel meta-heuristic algorithm for optimal design of water distribution networks. Swarmand Evolutionary Computation, 17: 14-24. https://doi.org/10.1016/j.swevo.2014.02.002

[89] Jaramillo, A., Crawford, B., Soto, R., Villablanca, S.M., Rubio, A.G., Salas, J., Olguin, E. (2016). Solving the set covering problem with the soccer league competition algorithm. Springer International Publishing, Switzerland. 
[90] Moosavian, N., Moosavian, H. (2017). Testing soccer league competition algorithm in comparison with ten popular meta-heuristic algorithm for sizing optimization of truss structures. IJE Transactions A: Basics, 30(7): 926-936. https://doi.org/10.5829/ije.2017.30.07a.01

[91] Emami, H., Derakhshan, F. (2015). Election algorithm: A new socio-politically inspired strategy. IOS Press and AI Communications, 28: 591-603. https://doi.org/10.3233/AIC-140652

[92] Louchard, G., Ward, M.D. (2015). The truncated geometric election algorithm: Duration of the election. Statistics and Probability Letters, 101: 40-48. https://doi.org/10.1016/j.spl.2015.02.018

[93] Liu, Z.Z., Chu, D.H., Song, C., Xue, X., Bao, Y.L. (2016). Social learning optimization (SLO) algorithm paradigm and its application in QoS aware cloud service composition. The Journal of Information Sciences, 326: 315-333. https://doi.org/10.1016/j.ins.2015.08.004

[94] Gong, Y.J., Zhang, J., Li, Y. (2014). From the social learning theory to a social learning algorithm for global optimization. 2014 IEEE International Conference on Systems, Man, and Cybernetics (SMC), San Diego, CA, pp. $222-227$ https://doi.org/10.1109/SMC.2014.6973911

[95] Montes de Oca, M.A., Stutzle, T. (2008). Towards incremental social learning in optimization and multiagent systems. Proceedings of the 10th Annual
Conference Companion on Genetic and Evolutionary Computation, pp. 1939-1944. http://doi.acm.org/10.1145/1388969.1389004

[96] Satapathy, S., Naik, A. (2016). Social group optimization (SGO): A new population evolutionary optimization technique. The Journal of Complex Intelligence System, 2(1): 73-203. https://doi.org/10.1007/s40747-016-00228

[97] Feng, X., Wang, Y.B., Yu, H.Q., Luo, F. (2016). A novel intelligence algorithm based on the social group optimization behaviors. IEEE Transactions on Systems, Man, and Cybernetics: Systems, 48(1): 65-76. https://doi.org/10.1109/TSMC.2016.2586973

[98] Balochian, S., Baloochian, H. (2019). Social mimic optimization algorithm and engineering applications. The Journal of Expert Systems with Applications, 134: 178-191. https://doi.org/10.1016/j.eswa.2019.05.035

[99] Madhavi, G., Harika, V. (2018). Implementation of social group optimization to economic load dispatch problem. International Journal of Applied Engineering Research, 13: 11195-11200.

[100] Huan, T.T., Kulkarni, A.J., Kanesan, J., Huang, C.J., Abraham, A. (2016). Ideology algorithm: A socioinspired optimization methodology. Natural Computing Applications, 28: 845-876. 